\title{
Correspondence
}

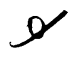

Letters to the Editor should not exceed 500 words.

In Front of the Public

C. C. Crampton, F.F.A. R.C.S. .............741

Penicillin in Poultry Feed

Naomi Datta, M.D. ........................741

Brucellosis Still Spreading

A. E. Wright, M.C.PATH. ; J. Reynolds,

A.P.H. ...................................741

Freezing and Antilymphocytic Globulin

W. J. Dempster, F.R.c.s. ..................742

High Optical Density of Liquor Amnii

C. R. Whitfield, F.R.C.o.G. ...............742

Adequacy of Man

E. R. C. Walker, F.R.C.P.ED. ..............742

Rhesus Sensitization and Abortion

C. A. Clarke, F.R.C.P., and P. M. Sheppard,

D.PHIL. .................................. 743
Oral Contraceptives Containing Oestrogens

E. F. Scowen, F.R.C.P. ....................744

Value of Osteopathy

P. Jacobs, M.R.C.P. ; A. Stoddard,

D.PHYS.MED. …..........................744

Tracheal Intubation

C. L. Hewer, F.F.A. R.C.S. .................744

Feto-maternal Bleeding and Hypertension in

Pregnancy

mann, M.D.

Fluid Therapy during Surgery

P. J. Horsey, F.F.A. R.C.S. 745

Representative System for Hospital Junior

Doctors

A. C. D. Brown, M.B. ...................745

Equality : Nothing for Everyone?

A. V. Russell, M.B. .......................745
Post-registration Training of General

Practitioners

A. Cavendish, F.R.C.s.

Specialist Registers

D. J. Hudson, M.B.

The Consultant's Job

W. D. Park, F.R.C.S. ; C. G. Eastwood, $\frac{0}{3}$

W. D. Park, F.R.C.S. ; C. G. Eastwood,

G.P. Remuneration in N. Ireland

W. B. Jamison, M.B. …................7

light of Commonwealth Graduates in U.K.

P. W. Hutton, F.R.C.P.

Pensions and Superannuation

A. A. Graham, M.B.

Christmas Gifts Fund Appeal

G. H. Bateman, F.R.C.S.

\section{In Front of the Public}

SIR,-Some days ago, while in non-medical company, I watched a well-known weekly television programme during which three medical participants discussed the possible dangerous effects of the contraceptive pill on the female body.

I would not wish to go into the ethics of medical men allowing their names and appointments to be publicly broadcast, or into the advisability of leaving countless women with grave doubts about the dangers or otherwise of the pill. I am, however, deeply con- cerned with the sight of eminent medical men criticizing each other's views and experience publicly in front of a lay audience. The cutand-thrust of medical argument on a combined ward round, or at a medical meeting, can be informative often and amusing occasionally; but similar repartee broadcast by television can only help to drag British medical prestige to an even lower level than that which it has already reached.-I am, etc.,

Waltham Cross, Herts. C. C. CRAMPTON.

\section{Penicillin in Poultry Feed}

SIR,-The Government has accepted the recommendation of the Swann committee that the use of the medically important antibiotics penicillin, chlortetracycline, and oxytetracycline as feed additives for the promotion of growth in pigs and poultry be discontinued (29 November, p. 511). ${ }^{1}$ In the case of the tetracyclines a basis for the recommendation is the fact that Escherichia coli from the faeces of tetracycline-fed pigs and poultry is almost entirely tetracycline-resistant, the resistance being transmissible to other intestinal bacteria including human pathogens. ${ }^{2}$

In the case of penicillin a similar basis would be the emergence of ampicillin-resistant intestinal bacteria in penicillin-fed livestock (Report, para. 9-15). Anderson and I suggested that penicillin might have had this effect when we found $R$ factors giving ampicillin-resistance in cultures of salmonella isolated from pigs, but we had no direct evidence that penicillin in pig feed was responsible for the ampicillin-resistance. The high incidence of ampicillin-resistance in salmonella subsequently found by Anderson most probably resulted from the prophylactic and therapeutic use of ampicillin in calves, rather than from penicillin as a food additive.

Penicillin at a " nutritional" dose level does not lead to the development of ampicillin resistance in the normal intestinal Escherichia coli of chicken. As part of a study intended to look for any enhanced incidence of infection with resistant bacteria in poultry packers, cloacal swabs were recently taken from 48 broiler chickens, fed all their lives on pelleted food containing $10 \mathrm{~g}$. penicillin/ton, and from 30 breeder fowl which had never received penicillins. Neither group had ever been fed tetracyclines. The birds came from several different farms, and specimens were collected at the packing station where they were to be killed. The swabs were cultured on media for the selection of drug-resistant E. coli. No ampicillin-resistant strains were detected from any specimen, although $E$. coli with multiple and transmissible drug-resistance, not including ampicillin-resistance, was common in both groups.

The proposed ban on penicillin as a feed additive thus rests only on the raised rate of carriage of penicillin-resistant Staphylococcus aureus by penicillin-fed livestock and their human attendants ${ }^{5}$ and on the possibility, not directly demonstrated, that penicillinfeeding may lead to the emergence in

livestock of ampicillin-resistant salmonel Penicillin is cheap, home-produced, and effective in promoting growth in young anit

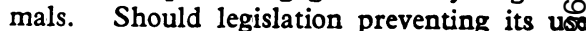
in feeds be introduced without clearer evidence for undesirable side-effects ?-I ang etc.,

Department of Pathology, NAOMI DATta. Royal Postgraduate Medical School, London $\mathrm{W} .12$.

\section{REFERENCES} Ant Joint Committee on the Use Antibiotics in Animal Husbandry and Veterina? Smith, H. W Nature, 1968 H.M.S.O.

3 Anderson, E. S., Nature, 1968, 218, 728.

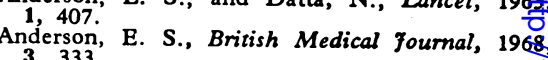
Smith, H. W., and Crabb, W. E., fournal Pathology and Bacteriology, 1960, 79, 243 .

\section{Brucellosis Still Spreading}

SIR,-Your leading article (29 Novembee p. 512) and the article by Dr. R. J. Hendersan (p. 550) highlight a problem which shoug cause us all concern. Brucellosis is a disea which can be prevented, but the regulations. present in force are so difficult to adminiso ter that it is unlikely we shall eradicate in the foreseeable future. Indeed, the volur tary eradication scheme may lead to dio semination of infection, as Dr. Henders rightly points out: The following saga illus trates these points.

A year ago a routine raw milk sample $e \bar{y}$ amined in this laboratory gave a positive ring test (M.R.T.) for antibodies to brucellos To confirm infection individual cow sampl were examined and one of these yielded $B \Phi$ abortus on culture. Before action could be takes, indeed before the medical officer of health hat been informed of the result, the cow was soldo a perfectly legal step for the farmer to take eve if he knew it was infected. A month later th incident was repeated and was followed by request from the farmer for milk to be examine from six recently purchased beasts. Br. abortus 
was isolated from one of these and this animal was therefore also sold on the open market.

Further samples at this stage were negative, and over the following months a series of doubtful positive M.R.T.s culminating in a single positive guinea-pig were the only results of much hard work. The positive test obtained through the guinea-pig was of course useless owing to the time interval, for the law requires action within 42 days. The discovery of more strongly positive M.R.T.s, together with the history of the herd, determined the medical officer of health to take action. Accordingly a pasteurization order was imposed and fortunately $\mathrm{Br}$. abortus was cultured a day or two later, confirming the justice of the order.

At the end of 12 months the balance-shee read as follows: On the debit side the laboratory had, in the course of the year, examined some 500 specimens from the farm. This involved a considerable expenditure in tim and media and also the slaughter of a num ber of guinea-pigs. The specimens had been collected by milk samplers driving a heavy mileage at public expense. A local public heath inspector had a seven-week illness diagnosed as undulant fever following hi visits to the farm. Several brucella-positive cows had been sold to unsuspecting farmers possibly residing in adjoining counties.

There seemed at that stage little on the credit side except that some student technicians had learned to culture and identify $B r$. abortus. More recently, however, there has been a substantial gain, for the farmer has installed a pasteurization plant and in future will market heat-treated milk. The problem on one farm has been solved, but there remains the problem of the sale of the brucella-infected cows. Perhaps at this moment Dr. Henderson in Worcester, or one of our colleagues in Hereford or Oxford, is investigating a positive M.R.T. from a herd previously free from brucellosis.-I am, etc.,

$$
\begin{aligned}
& \text { Public Health Laboratory, A. E. WRIGHT. } \\
& \text { Glos. }
\end{aligned}
$$

Dr. R. J. Henderson's article (29 November, p. 550) expressing cause for concern because of trading in brucella-infected cattle is timely. I, too, have personal experience of brucella-infected beasts being sold and have been able to do nothing about it

With the advent of the Milk (Special Designation) Regulations, 1963,' I thought would be able to exercise some control. Schedule 2 of these regulations made it a condition applicable to a producer's licence that the producer should keep a record of all infected animals segregated from the herd, and in the case of removal the manner in which the animals had been disposed of. I regret that although producers may keep such a record the Ministry of Agriculture, Fisheries and Food informed me that as the licensing authority the Ministry had no authority for making these records available to me. Had the records been available I could have informed the medical officer of health in the district to which the infected cattle had been moved, but have had to accept that the Ministry is not interested in the control of selling brucella-infected cattle. -I am, etc.,

\section{Warmister and Westbury Rural District Co
Warminster, Wilts.}

JosepH REYNOLDS.

\section{RBFERENCB} The Milk (Special Designation) Regulations,1963,
1963, S.I. No. 1571. London, H.M.S.O.

\section{Freezing and Antilymphocytic Globulin}

SIR,-The use by Dr. P. B. Doak and his colleagues (29 November, p. 522) of frozen spleen and thymic cells $\left(-30^{\circ}\right.$ C.) for the preparation of antilymphocytic globulin (A.L.G.) raises some interesting theoretical points.

In a survey of published reports on the technique of preparing A.L.G. I had been struck by the play several authors ${ }^{1-3}$ made about the percentage viability of the lymphocytes prior to injection into horses. In a recent and detailed review of this subject no mention was made of the suitability of frozen lymphocytes for the production of A.L.G What was pointed out was that lymphocytes were frozen but protected by dimethylsulphoxide and later were thawed and used in the successful production of A.L.G. Dr. Doak and his colleagues not only used straight frozen spleens and thymuses, but, compared to some other authors, used fewer cells and without Freund's adjuvant - the immunologist's best friend. Does this mean that there are potent subcellular fractions which can remain stable under frozen conditions without protection and yet sensitize after thawing ? After freezing without protection the lymphocytes per se would not be viable. Surely, then, any frozen parenchymal cell could be used to sensitize horses for A.L.G. production?

Medawar ${ }^{1}$ found that subcellular fraction were inactive after freezing. It was later reported that a factor in urine was inactive as a transplantation sensitizing agent after freezing, and this could rule out mucopolysaccharide as the transplant antigen determinant since this substance is stable at very low temperatures. ${ }^{6}$ This was disconcerting, since the damage to the second-set kidney is mainly on the basement membrane of glomeruli $^{7}$ even when the animals have been presensitized with skin allografts. ${ }^{8}$ In all the discussions on how A.L.G. works it has been overlooked that, although Inderbitzin $^{9}$ reported that A.L.G. could suppress the tuberculin reaction, we have previously shown that total body $x$-irradiation could achieve the same result more effectively and on successive occasions. ${ }^{10}$ And who knows exactly how $x$-irradiation suppresses immunological reactions?

A diagnosis by Dr. Doak and his colleagues of lung infection due to Pneumocystis carini is reasonable. A mere lung infection was not implied in the original description of the "lung-transplant syndrome." Interesting as the concept of an allograft reaction presenting simultaneously in an organ of the host may be, the lack of scientific data in support of this syndrome has been pointed out. ${ }^{11}$ I am, etc.,

\section{W. J. Dempster.}

\section{Royal Postgraduate Medical School} London W.12.

\section{REFERENCES} 1 Abaza, H. M., Nolan, B., Watt, J. G., and 4,618

Nodruff, M. F. A., Reid, B., and James, K. Nature, 1967, 215, 591.

$97,323$.

James, K., Progress in Surgery, 1969, $7,140$.

Medawar, P. B., Biological Problems of Grafting, 1959, edited by F. Albert and P. B. Medawar, p. 6. Oxford, Blackwell Scientific Publications.

Lancet, $196 \mathrm{i}, \mathrm{1}, 1031$. $1953,40,447$. . British fournal of Plastic Sur gery, $1953,5,228$

nderbitzin T International Archives of Allergy and Applied Immunology, 1956, 8, 150. 10 Lennox, B., Dempster, W. J., and Boag, J. W.,
British fournal of Experimental Pathology,
$1952,33,380$. B., and Dempster, W. J., British
. Hughes, J. M. B., and
Medical fournal, 1968, 1, 250.

\section{High Optical Density of Liquor Amnii}

SIR,-The case report by Drs. J. M. White and R. W. Jones (22 November, p. 473), in which they record a high optical density difference at $450 \mathrm{~m} \mu$ in the liquor amnii of a pregnant Greek Cypriot with $\mathrm{Hb} \mathrm{H}$ disease, is of great interest, but I feel they dismiss too readily the possibility (or probability) that the excessive liquor bilirubin was maternal in origin.

In this hospital an even higher optical density difference for bilirubin was found in a woman with congenital haemolytic anaemia. As she had also developed antiKell antibodies, probably as a result of one of her many blood transfusions for recurrent severe anaemia, amniotic fluid analysis was scheduled for the 30th week of pregnancy. Amniocentesis was performed as planned even though a haemolytic crisis, with transient jaundice, began the previous day. The liquor optical density difference at 450 $\mathrm{m} \mu$ was 0.44 , a level usually indicating a hopelessly severe degree of fetal haemolytic disease. As and after the serum bilirubin returned to normal levels, repeated amniocenteses revealed a rapid decline in liquor bilirubin and delivery near term was intended. Labour began spontaneously at 36 weeks and the baby survived without any evidence of haemolysis.

A high liquor optical density difference at $450 \mathrm{~m} \mu(0.24$ at 32 weeks $)$ has also been observed in a rhesus-sensitized woman with infectious hepatitis and with an unaffected baby (Coombs negative; rhesus negative).

It is clear that obstetricians dealing with the rhesus problem should be aware that maternal haemolysis, or hyperbilirubinaemia from some other cause, may be associated with high bilirubin levels in the liquor amnii.-I am, etc.

Royal Maternity Hospital,

Belfast.

\section{Adequacy of Man}

SIR,-Some weeks ago you commented editorially (6 September, p. 546) on Sir Peter Medawar's presidential address to the British Association this autumn,' suggesting that it might stimulate "thought on the human condition-and on the contribution doctors may make to alleviate it. . . ." It is interesting to recall, in the context of $\mathrm{Sir}$ Peter's comparisons between the seventeenth and the present centuries, that it was in the first half of that century that the philosopher Descartes expressed the view that "it is to the science and art of medicine that the human race must look if it is to perfect and fit itself for the gigantic social tasks and problems which are bound up with its future development.",

Descartes himself would have been the last to approve uncritical acceptance of his view. For him questioning doubt (Cartesian doubt) was the starting-point of philosophic inquiry, the test we should be ready to apply at all 